\section{Scared to life}

$\mathrm{F}$ ar too many people waltz through life, upcast and uptrodden, happier than a cow at a vegan barbecue. But they shouldn't be happy. They should be dismayed, distressed and disturbed. They should be panic-stricken, perturbed and petrified. They should, in short, be several of the words that came up when I typed "afraid" into thesaurus.reference.com.

How can anyone even pretend that life is grand, when every other day a new item enters the list of "epidemics" that threaten to send thousands of us on the express train to Dirtnapville? These problems will linger forever, maybe longer, unless the public is brought to a frothing panic. Change will only come through fear, a motivator unmatched in power, not counting Starbucks gift cards.

So why aren't more of us living in a healthy state of perpetual dread? Look no further than your nearest public health office. Sure, public health physicians dole out warnings - you'll get sick unless you wash your hands; you'll get cancer unless you quit smoking; you'll become obese unless you avoid foods that taste good. But we don't listen. Why? Because doctors speak a language that, in the fear department, ranks somewhere between infant coos and kitten mews.

If public health physicians want people to live, they must learn how to scare people to death. And that starts with language. People are not going to eat healthier or quit smoking or sneeze into their sleeves until doctors start coming up with scarier names for public health problems.

This year, the most pressing health problem is, of course, the $\mathrm{H} 1 \mathrm{~N} 1 \mathrm{flu}$ pandemic. But does the term "H1N1" strike fear in your heart? Does it make you want to take all necessary precautions to avoid catching it? Probably not.

There is nothing scary about the term "H1N1." It sounds like the name of an income tax form, or a robot that might hang out with R2D2 in Star Wars. Even worse, if you were to mis- take each " 1 " in "H1N1" for the letter "I," it would form the word "hini." That's similar to "heinie," which, let's face it, is a really funny word. Warning the public about the heinie flu would only result in an outbreak of giggles.

Doctors weren't always so bad at naming illnesses. There was a time when pandemics were given terrifying names, such as The Black Death. The 14th century had its challenges - inadequate sanitation systems, spotty Internet service — but, boy, could they name a pandemic back then.

Imagine telling a group of 13year-old boys to frequently wash their hands or risk catching the H1N1 flu. It would be glazed eyes and shoulder shrugs all around. Now imagine that, instead, you warned them to lather up or face The Black Death. Those boys would scrub so hard and so often that, after a week, their hands would be nothing but tendons and bones.

Nearly all recent public health problems have been saddled with banal names. There was SARS. (Acronyms = not scary.) Then there was the bird flu, and we all know how terrifying birds are. What's next? The fluffy bunny flu?

We can do better. Finding serious names for serious problems is not that difficult. The phrase "The Black Death," which is simply a dark colour followed by a fear-inducing word, could serve as a model. Doctors could, for instance, call the next pandemic The Navy Annihilation, or The Maroon Scourge, or The Indigo Calamity.

Doctors must do more than just educate the public. Information is not enough. We already know about the dangers of obesity, but we continue to stuff our gullets with french fries and doughnuts. We already know that washing our hands prevents the spread of flu, but we are too lazy to reach for the soap. We already know that setting

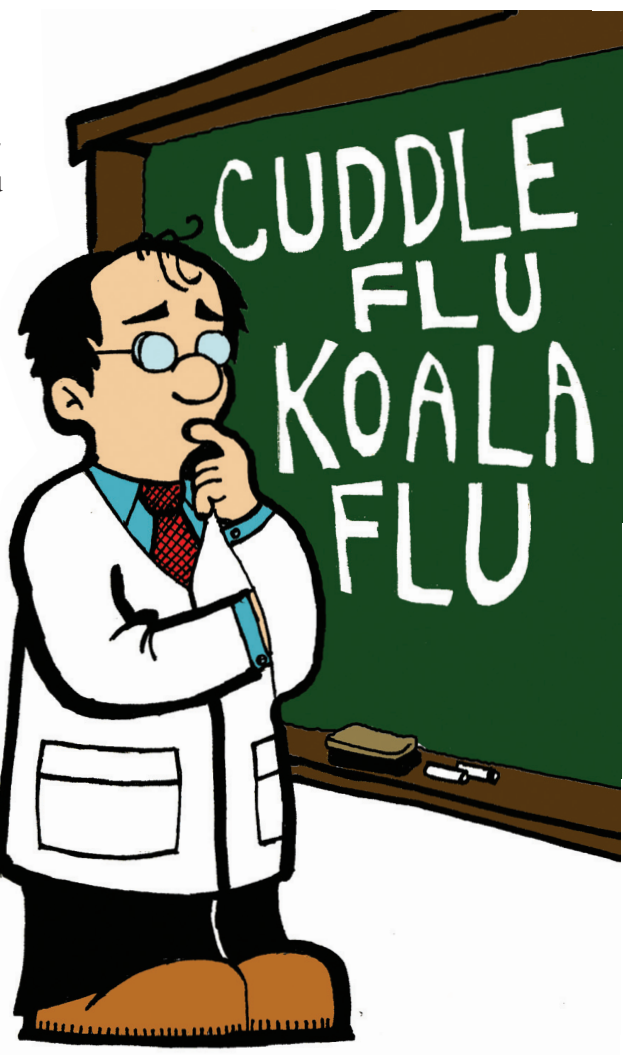

off fireworks in the living room is dangerous, but we still do it because couches are comfortable and explosions are super cool.

Human beings are creatures of habit, and we will not change until the medical community scares us into changing. Doctors, please - no more H1N1; no more SARS; no more bird flu. Enough with the lame names. Frighten us, for our own good. The greatest thing we have to fear is not being afraid enough.

\section{Roger Collier BEng \\ News journalist \\ CMAJ}

Have you got an opinion about this article? Post your views at cmaj.ca. Potential Salon contributors are welcome to send a query to salon@cmaj.ca.

All editorial matter in CMAJ represents the opinions of the authors and not necessarily those of the Canadian Medical Association. 